\title{
O papel da imaginação como estratégia educativa em Maria e seus bonecos e As aventuras do avião vermelho
}

\author{
El papel de la imaginación como estrategia educativa en Maria e seus bonecos
} y As aventuras do aviao vermelho

\section{Edwirgens Aparecida Ribeiro Lopes de Almeida Regina Queiroz de Oliveira}

Universidade Estadual de Montes Claros - UNIMONTES - Montes Claros - Minas Gerais - Brasil

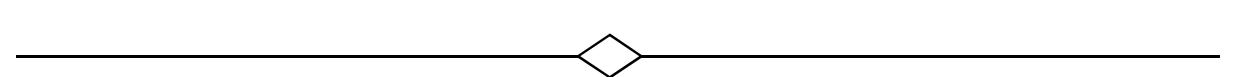

Resumo: A presente pesquisa integra o projeto "A literatura infantil de Lúcia Miguel Pereira- uma escrita da tradição?" que investiga os recursos adotados pela autora e crítica literária na composição de suas narrativas destinada aos pequenos leitores. Este texto tem como objetivo estudar a relevância da família e a configuração do espaço para a educação infantil nas viagens imaginárias da criança nas obras Maria e seus bonecos, de Lúcia Miguel Pereira, comparando-a às estratégias literárias adotadas pelo seu contemporâneo Érico Veríssimo, quando compôs a narrativa As aventuras do avião vermelho. Para isso, serão revisitadas leituras sobre os dois autores citados acima, bem como nos cercaremos de discussões críticas e teóricas em torno da literatura infantil tendo como referência o pensamento de Antonieta Cunha, Philippe Ariès, Regina Zilberman e Nelly Novaes Coelho, dentre outros.

Palavras-chave: Literatura infantil. Educação. Imaginação. Fantasia.

Resumen: La presente investigación integra el proyecto "A literatura infantil de Lúcia Miguel Pereira- uma escrita da tradição?" que investiga los recursos adoptados por la autora y critica literaria en la composición de sus narrativas destinadas a los pequenos lectores. Este texto tiene como objetivo estudiar la relevância de la familia y la configuración del espacio para la educación infantil en los viajes imaginarios de la niña/niño en las obras Maria e seus bonecos, de Lúcia Miguel Pereira comparándola a las estratégias literárias adoptadas por su conteporáneo, Érico Veríssimo, cuando compuso da narrativa As aventuras do avião vermelho. Para ello, serán revisitadas lecturas sobre los dos autores citados arriba, así como nos cercaremos de discusiones críticas y teóricas al rededor de la literatura infantil tomando como referencia el pensamento de Antonieta Cunha, Philippe Ariès, Regina Zilberman y Nelly Novaes Coelho, entre outros.

Palabras-clave: Literatura infantil. Educación. Imaginación. Fantasía. 


\section{Introdução}

De acordo com Antonieta Cunha (1994), a literatura infantil começa a se delinear no início do século XVIII, quando a criança passa a ser considerada como um ser diferente do adulto, época da reorganização do ensino e da fundação do sistema educacional burguês. Antes disso, as crianças acompanhavam a vida social dos adultos uma vez que estes ignoravam a existência das peculiaridades da infância e do mundo infantil.

Foi a partir do século XVII que a literatura infantil surgiu, pois, antes desse período, não se pensava em escrever para crianças em razão de não se ter uma concepção definitiva de infância. Segundo essa linha de pensamento, no período medieval, sobretudo no século XII, a sociedade não tinha uma consciência de particularização infantil. Não havia uma distinção entre os pequenos e o adulto. Logo que a criança apresentasse condições de viver sem o cuidado constante da mãe, ingressava na sociedade dos adultos e não se distinguia mais deles.

Conforme registra Philippe Ariès (1981), o desconhecer desta fase da vida também era representada na pintura, uma vez que as crianças não eram caracterizadas com a sua expressão particular, mas retratadas como adultos em miniatura. Somente no século XIII, iniciou-se a descoberta da infância. No entanto, os sinais de seu desenvolvimento tornaram-se realmente numerosas e significativas a partir do fim do século XVI e durante 0 século XVII. As brincadeiras eram representadas através da pintura, as quais utilizavam crianças com cavalo de pau e com cata-vento. Porém, essas brincadeiras atingiam apenas a primeira infância, porque, depois dos três ou quatro anos, elas diminuíam e logo eram abandonadas. Como argumenta Ariès, a partir dessa idade, "a criança jogava os mesmos jogos e participavam das mesmas brincadeiras dos adultos, quer entre crianças, quer misturadas aos adultos" (ARIÈS, 1981, p. 49). Dentre as brincadeiras do universo adulto de que as crianças participavam, estava a de ouvir pequenas narrações, os "contos de fadas", transmitidos oralmente por um contador de histórias.

No entanto, foi durante o século XVIII que a literatura infantil teve o seu real aparecimento, em virtude do novo papel que se estabelecia entre os integrantes da sociedade desse período. A criança ganhou um novo espaço após a ascensão da burguesia no continente europeu. Além de crescimento da capacidade econômica, a burguesia também conquistou mais poder político que fez com que organizasse uma nova ordem social e cultural.

Diante dessa reorganização social, os adultos começaram a se preocupar não só com a sua saúde, mas também, com investimentos na sua educação, de forma que se preparassem para a vida. Sendo assim, o pequeno passou a assumir um lugar importante no meio familiar e se tornou o centro das atenções. Contudo, o adulto se concentrava apenas na preparação dos pequenos para o futuro. Como afirma Ariès:

Encontramos aí ao mesmo tempo elementos de conduta infantil e conselhos morais, que hoje julgaríamos inacessíveis às crianças. Isso explica pelas origens dos manuais de civilidade, que eram, em suma, registros dos costumes da aprendizagem, ainda muito influenciado pelos hábitos de uma época em que não se dosava a matéria transmitida às crianças, em que estas eram logo completamente mergulhadas na sociedade: tudo lhes era dado desde o início. As crianças misturavam-se imediatamente aos adultos (ARIÈS, 1981, p. 172)

Sendo assim, às crianças eram lidos tais manuais de caráter pedagógico e, também, Ihes eram contadas histórias que apresentavam lições moralistas. As narrativas lidas para as crianças tinham como objetivo transmitir os valores da sociedade da época. Dessa maneira, foi no século XIX que a literatura infantil passou a se caracterizar como literatura destinada ao público infantil simplesmente pela arte de agradar, de despertar o interesse e prender a atenção da criança.

Nos dias atuais, para Ricardo Azevedo (1999), a criança é vista como um ser diferente do adulto, diferenciando na idade, na maturidade, além de ter certos comportamentos típicos. Porém, além da idade, o limite entre a criança e o adulto é complexo, 
pois este limite está associado à cultura, ao momento histórico e aos papéis determinados pela sociedade. Estes papéis dependem da classe social e econômica em que está inserida a criança e sua família.

As crianças nascidas em lares "mais abastados" tinham acesso a uma educação particular, orientadas por preceptores, com acesso a uma vasta literatura clássica. Por outro lado, as crianças nascidas em lares menos privilegiados recebiam uma educação popular, passada de geração a geração por meio de histórias contadas, seja de cavalaria ou de aventuras e, neste panorama, emerge a literatura infantil, destinada à preparação da elite cultural por meio da adaptação dos clássicos e dos contos de fadas de natureza folclórica. Esta literatura se desenvolve levando a criança a uma compreensão acerca dos seres humanos, do mundo em que vive e sobre si mesma além, é claro, de exercer um importante papel lúdico. Vemos a partir de então, surgir uma literatura cuja preocupação central é a criança e o jovem.

\section{Desenvolvimento}

Sob tais pressupostos, em cada país, vão surgindo, aos poucos, propostas diferentes de obras literárias infantis. Entre os autores mais importantes podemos destacar, na Europa, Andersen, Carlo Collodi, Amicis, Lewis Carrol, J. M. Barrie, Mark Twain, Charles Dickens, Ferenc Molnar. No Brasil, Carlos Jansen, Figueiredo Pimentel, Coelho Neto, Olavo Bilac, Tales de Andrade e Monteiro Lobato. É a literatura de natureza, essencialmente, lúdica, devaneadora e mágica, cujo conteúdo se caracteriza pela improbabilidade e pela inverossimilhança. Ademais desses ficcionistas brasileiros citados, podemos encontrar Jorge Amado e Lúcia Miguel Pereira, dois grandes escritores que se dedicaram tanto à escrita destinada aos adultos quanto aos pequenos nas décadas de 30 e de 40, mas que não são muito estudados em se tratando dessa ficção infantil.

Nessa perspectiva, este estudo pretende um passeio pelas obras Maria e seus bonecos, de Lúcia
Miguel Pereira e As Aventuras do avião vermelho, de Érico Veríssimo, tendo em conta que os brinquedos são antropomorfizados para auxiliar na educação das crianças, por meio da imaginação e da fantasia. Vale observar que, através das viagens imaginárias, os brinquedos e os animais levam ensinamentos às crianças, como respeito, educação geográfica e ecológica, o que vem a caracterizar o aspecto também pedagógico nesses textos infantis.

De acordo com a concepção de Dirce Lorimier Fernandes (2003), através do texto, um maravilhoso universo se abre para a criança, recheado de faz-deconta, de sonho, de imaginação em que o mito e o mistério envolvem atividades meramente recreativas. A criança mergulha num mundo de pureza, de encanto, de ingenuidade e de curiosidade. Impregnando-se de espanto e de admiração frente a um espaço encantado com seres fantásticos que dão voz e vida a magos, a feiticeiros, a anões, a gigantes, a bruxas, a princesas e a castelos extraordinários que empolgam os corações dos pequenos e fazem seus olhos brilharem.

Pensando nessa perspectiva de uma escrita destinada ao público infantil, essa pesquisa resgata a escrita de Lúcia Miguel Pereira e de Érico Veríssimo que apresentam características semelhantes, enfatizando a imersão das crianças no mundo da fantasia. Essa intervenção também envolve a própria família, na medida em que a criança a convence de adquirir e administrar a liberdade de desvendar segredos intrigantes, trazendo os adultos para o seu universo infantil, sempre cheio de curiosidades.

Tecendo uma relação entre a família e o espaço para a educação infantil, trazemos para esta pesquisa a seguinte questão: qual o papel da imaginação como estratégia educativa em Maria $e$ seus bonecos, escrita por Lúcia Miguel Pereira e As Aventuras do avião vermelho, de autoria de Érico Veríssimo?

Diante do desafio proposto, não temos, de nenhuma maneira, a pretensão de sermos conclusivos. Apenas promover um novo olhar sobre a infância e sobre o papel que as obras supracitadas alcançam ao serem utilizadas como instrumento que 
divertem e que, por sua vez, também ensinam. Esperamos chegar à conclusão de que a fantasia infantil é também uma mensagem para o adulto. Mensagem de um mundo melhor e mais divertido.

Partindo dessa perspectiva, é lícito esclarecer que o escritor Érico Veríssimo, que se dizia ser apenas um contador de histórias, contou muitas histórias para gente grande em livros como Olhai os lírios do campo (1938), O tempo e o vento (1948), O senhor embaixador (1965), Incidente em antares (1967) e O escritor diante do espelho (1956). Mas também gostava de contar histórias para crianças em livros como As aventuras do avião vermelho (1936), Fantoches (1932) e O urso com a música na barriga (1938), Rosa Maria no castelo encantado, Os três porquinhos pobres, O elefante Basílio, dentre outros.

Veríssimo nasceu em Cruz Alta, no interior do Rio Grande do Sul, em 1905. Antes de ser escritor, fez muitas coisas. Trabalhou no comércio, foi bancário e se tornou sócio de uma pequena farmácia que foi à falência porque ele preferia ficar lendo livros a vender os remédios.

Quando se mudou para Porto Alegre, Érico Veríssimo foi trabalhar na Revista do Globo, que era publicada pela livraria homônima. Depois nasceu a Editora Globo, que ele ajudou a criar e a se tornar uma das mais importantes do país e que editou todos os seus livros, desde o primeiro, intitulado Fantoches.

Ele é considerado um dos melhores escritores brasileiros da sua época, e foi um dos mais populares. Muito dos seus livros foram traduzidos em outras línguas. Érico Veríssimo contou suas histórias para muita gente, desde crianças a adultos, conta Afrânio Coutinho (1999). O escritor morreu em Porto Alegre, em 1975, quando ia fazer 70 anos.

A obra As aventuras do avião vermelho, publicada em 1936, narra a história de Fernando, um menino que não era nada obediente. Para tentar resolver esse problema, o pai lhe dá um livro, o qual ele passa a tarde lendo e adora a história de um valente capitão tormenta, que percorre o mundo em um avião vermelho, realizando grandes aventuras.

De acordo com Regina Zilberman e Marisa Lajolo (2007), a escrita de Veríssimo apresenta muitos coloquialismos que se aproximam do discurso da criança, ao mesmo tempo em que se manifesta numa perspectiva intimista, isto é, traz em si uma reflexão psicológica das inquietações e frustrações vividas pelos pequenos protagonistas. Em seus textos, as histórias acontecem de forma simultânea em que é possível perceber o dinamismo. Sua obra vive uma fase urbana, já que o cotidiano da cidade é o pano de fundo para diversas discussões. Dessa forma: Entre os livros de Menotti del Picchia e os de
Érico Veríssimo, a semelhança é mais que
uma coincidência: as Viagens de João Peralta
e Pé-de-Moleque (1931) e As Aventuras do
avião vermelho (1936), os heróis são
fascinados por aviões e aventuras aéreas
lidas em obras de ficção. E, motivados por
essa atração, simultaneamente tecnológica e
literária, eles acabam realizando seus anseios
através da obtenção do objeto desejado - o
avião (de brinquedo, na narrativa de Érico) - e
da fuga de casa, atravessando os reinos mais
diversos: o espacial, o subterrâneo e o
aquático. Os meninos dão vazão a seu
imaginário, que exige o abandono do lar, cuja
vida prosaica é insatisfatória, e iniciam um
percurso por regiões mágicas, as quais são
mais interessantes que a existência doméstica
limitadora (ZILBERMAN, LAJOLO, 2007,
p.65).

Regina Zilbermam e Marisa Lajolo (2007) abordam que, na ficção de Érico Veríssimo, a fantasia é estimulada pelo aborrecimento doméstico, simbolizado pelos ambientes fechados em que nas histórias os heróis são fascinados por aviões e aventuras aéreas lidas em obras de ficção e, motivado por essa atração, simultaneamente tecnológica e literária, eles acabam realizando seus anseios através da obtenção do objeto desejado - o avião de brinquedo - na narrativa de Érico Veríssimo que é também objeto de fuga. No diálogo com o pai, o personagem Fernandinho expõe:

\footnotetext{
- Papai, quero um avião. Prometo não fazer mais travessuras.

Papai beijou Fernandinho e disse que ia trazer-Ihe um lindo avião.

[...] - Papai - disse Fernandinho com voz tremida -, eu tenho vontade de viajar de avião.

Papai passou a mão pelos cabelos do filho.

- Pois sim, meu querido, quando ficares grande poderás entrar num avião (VERÍSSIMO, 2003, p. 6-12).
}

Tendo em vista que a criança vive intensamente seus momentos ao brincar, ela constrói 
uma história que permite o diálogo com suas questões interiores e exteriores de maneira mágica. Sendo assim, ela possibilita uma fuga da realidade através das viagens imaginárias proporcionando 0 recriar de acordo com seus desejos de um outro mundo. Quando a criança participa da história através da leitura, ela acredita que seus conflitos podem ser solucionados da mesma forma, pois sua capacidade imaginária cria elementos e situações enquanto brinca. Ao revisitar esses anseios da criança, o intimismo se torna proeminente nessa narrativa em questão. Além disso, a história pode apresentar situações do cotidiano e resolvê-los de forma mágica, permite que ele participe da aventura e também ative sua criatividade para transformar o real, criando uma nova situação no plano da imaginação. Dá seguimento o diálogo entre pai e filho, na obra de Veríssimo:

- Papai passa a mão pela cabeça de Fernando e disse:

- Olha, se tu te portares bem hoje à hora do almoço, quando eu vier da rua te trago um livro de histórias.

- Traz mesmo, papai?

- Trago.

- Então eu fico bem quietinho.

E ficou mesmo. Não deu um pio. Não mexeu em nada à hora do almoço. Parecia até um bonequinho de açúcar.

De tarde ganhou o livro. Foi para cima da cama. Deitou-se de barriga para baixo, fincou os cotovelos no colchão, abriu o livro, segurou as bochechas com as mãos e começou a ver as figuras coloridas (VERÍSSIMO, 2003, p. 4$5)$.

Percebemos que, em troca do bom comportamento do filho, o pai de Fernando Ihe dá um livro com a história de um aviador. Através desta, o menino acaba gostando de avião e também quer transformar-se em um capitão. Essa estratégia usada faz com que, através das brincadeiras, Fernando mude completamente o comportamento com os pais, contribuindo em sua interação social e familiar. Nesse ponto, vemos a arte literária se tornar também um instrumento pedagógico, ou melhor, ao mesmo tempo em que diverte, entretém a criança, também educa dentro dos padrões dos costumes exigidos pela família.

Ao ler o livro, o menino ficou pensativo e, por fim ficou triste, pois queria ser um aviador também e fazer viagens vivendo grandes aventuras como na história. Então teve uma ideia e procurou o pai para pedir um avião.
- Papai, quero um avião. Prometo não fazer mais travessuras.
Papai beijou Fernandinho e disse que ia trazer-Ihe um lindo avião.
- Quero um avião vermelho - explicou o menino.
Papai saiu e, ao voltar do trabalho, trouxe um avião embrulhado em um papel verde.
Quando viu o brinquedo, Fernandinho perdeu a fala, de tão contente... (VERÍSSIMO, 2003, p. 6-8).

Ao presentear o filho com o brinquedo, o pai de Fernando proporcionou a ele a oportunidade de viver grandes aventuras com seus amigos imaginários, obtendo a oportunidade de conhecer vários lugares, novas culturas e também interagir com outras pessoas, animais e, até mesmo, com pessoas que faziam parte do seu cotidiano. Vê-se aqui, a literatura exercendo o papel de alimento à imaginação e à criatividade da criança, fomentando a aprendizagem e inserindo o pequeno leitor no mundo da fantasia, aspecto frutífero ao crescimento emocional e intelectual.

Já a escritora Lúcia Miguel Pereira, embora não seja amplamente conhecida pelo público como ficcionista, foi uma pioneira no campo de nossa literatura de ficção nos primeiros anos do século $X X$. É uma escritora mineira e se destacou por seu trabalho de crítica e historiografia literária. Lúcia nasceu em 1901, crítica literária, biógrafa, romancista, tradutora e autora de romances e de contos infantis, iniciou seu trabalho crítico na imprensa literária na década de 30. Entre 1939 e 1943, escreve as obras: A fada menina, A floresta mágica, Maria e seus bonecos e $A$ filha do rio verde. Publicou ainda os romances Maria Luiza (1933), Em surdina (1933), Amanhecer (1938) e Cabra cega (1954), tendo o mérito de retratar a complexidade da psicologia humana e a batalha da mulher na conquista da própria liberdade, comenta Edwirgens A. Ribeiro Lopes de Almeida (2011).

O conto infantil Maria e seus bonecos, de Lúcia Miguel Pereira, datada do ano de 1943, narra a história da menina Maria, uma garota travessa, que comete atitudes recrimináveis com suas bonecas e, 
para a transformação de suas atitudes, acaba sendo reeducada pelas próprias bonecas através da imaginação.

De acordo com Edwirgens Aparecida Ribeiro Lopes de Almeida (2011), a escritora Lúcia Miguel Pereira percebe os limites da ideologia do autor e o desejo que o mesmo pode exercer sobre o pequeno leitor ao construir seu discurso. Sendo assim, aquele enunciado que se pretende moral, torna-se moralizante. Sobre esse caráter moralista no texto infantil, Lúcia Miguel Pereira prossegue discutindo que a literatura, por si só, apresenta certo caráter moralista, aspecto que tende a prevalecer no texto infantil.

Dessa maneira, a autora faz uso da tradição da escrita literária infantil para efetivar, no plano da ficção, o universo experimentado pela criança sem deixar de lado os elementos mágicos que também povoam aquele imaginário. Com esse argumento, anota que: "querer expulsar o irreal do mundo infantil é tentar - em vão - reduzir-lhe as dimensões, abafar-lhe as ressonâncias, empobrecê-lo, amesquinha-lo, querer subordina-lo estritamente a lógica é desconhecer o ímpeto criador da imaginação ainda não sofreada pela vida". Consciente dessa possível deformação dos dados da tradição ao desenvolver os sucessos da narrativa a fim de conquistar a imaginação da criança, a autora admite que o texto não pode ser meramente moral ou moralizante, mas pode, ao longo do seu desenvolvimento, inspirar contornos morais (ALMEIDA, 2017, p.39).

Adotando tais pressupostos, Lúcia Miguel Pereira e Érico Veríssimo enfatizam características semelhantes, onde a fantasia faz a história da realidade, e a imaginação enriquece a inteligência da criança e desperta fontes para uma boa educação social e familiar. Em Maria e seus bonecos, a protagonista Maria faz maldades com seus brinquedos e, na noite de natal, recebe um boneco que, junto com seus outros brinquedos, ganham vida à noite com a intenção de educar e punir a menina pelos seus maus atos com os próprios brinquedos e com todas as pessoas de seu círculo de relações. E a participação do boneco Juquinha é decisivo nessa empreitada de reeducação da menina. Ao ser questionada pela empregada da casa sobre seu comportamento violento contra o boneco, Maria, a personagem de Lúcia Miguel Pereira, reage com agressividade.

- Ora vejam só para que havia de dar essa levada! Até parece que o boneco é gente!

Bastou isso para fazer Maria ficar zangada.

- Não penso não, que eu não sou nenhuma boba... Sei muito bem que ele é de pano, cheio de farelo. E vou já mostrar como sei.

Antes que a empregada pudesse fazer um movimento, pegou a tesoura de unhas, levantou a camisinha do Juquinha e deu-lhe um talho no peito. Nossa senhora! O sangue jorrou, como de uma ferida. Maria ficou tremendo de susto. $\mathrm{E}$ de novo, quando enxugou o talho, o sangue the molhou os dedos, sentiu a mesma cousa esquisita das outras vezes: uma vontade de ser boa, de gostar dos outros, de não fazer mais maldades. Com o bonequinho no colo, saiu procurando a mãe para dar-lhe um beijo (PEREIRA, 1943, p.20).

Se o fragmento de Lúcia Miguel Pereira nos revela as primeiras mudanças comportamentais da menina Maria frente ao contato com o boneco Juquinha, o trecho abaixo nos põe diante de questionamentos comuns no mundo infantil, impressos nas páginas de Érico Veríssimo:

[...] o pai dele era engenheiro. Tinha um escritório cheio de máquinas, régua, compassos e outros aparelhos complicados. Fernandinho gostava muito de olhar o mapamúndi, que estava em cima da mesa.

- Certo dia, papai lhe mostrou o globo e disse:

- Meu filho, o mundo é assim redondo.

- Então o mundo é uma bola? - Perguntou Fernando.

- Sim senhor.

- Então, a gente podia brincar de jogar bola com o mundo?

papai desatou a rir.

- Não diga bobagens, menino! (VERÍSSIMO, 2003, p. 10-11).

Diante dessa citação, Érico Veríssimo, em sua obra, expõe a participação da família compartilhando com seu filho momentos de diversão. Dessa forma, usa estratégias para ajudar na educação do filho, presenteando-o com brinquedos em troca de bons modos e que lhe permita uma inserção no mundo imaginário fomentando início da aprendizagem da criança, assim como faz a autora Lúcia Miguel Pereira. Os brinquedos, nessas obras, são elementos importantes de aproximação do mundo infantil, promovem o entretenimento, mas também são utilizados como forma de promover a educação daquelas crianças. Conta o narrador de Maria e seus bonecos: "Com o barulho, a mãe acordou, e veio, 
toda assustada, saber o que estaria acontecendo no quarto da filha. Quando viu tanto brinquedo caro espalhado no chão, ficou muito triste... Dessa vez o pai zangou-se de verdade e disse que não comprava mais brinquedos para Maria estragar" (PEREIRA, 1943, p. 15).

Maria era uma menina muito má e se aborrecia com tudo. Quando se zangava, ninguém podia chegar perto dela, pois recebiam socos, pontapés, unhadas, parecia até maluca. Mas quem sofria mesmo com essa maldade eram seus brinquedos, que recebiam pontapés, socos, além de serem jogados e quebrados por ela. Porém, com a educação gradual que os brinquedos vão dando à Maria durante as noites, quando se tornam vivos e, com a participação de boneco Juquinha, a menina começa a apresentar perceptível mudança. Diante da mudança de comportamento da menina:

\begin{abstract}
- Quem ficou espantada, no outro dia, foi sua mãe, vendo Maria brincar com seus bonecos sem quebrar nenhum; deu uns puxões de cabelo e uns socos, mas isso não era nada, perto do que fazia sempre. Só da Shirley, de quem tinha ficado com mais raiva, é que arrancou dois dentes. Mordeu também o nariz do Pinóquio, mas tirou apenas um pedacinho. Em compensação, judiou com Clarinha a valer, e ainda por cima inventou que a outra Ihe tinha roubado uma bola (PEREIRA, 1943, p. 14).
\end{abstract}

Diante dessa citação, notamos que a menina Maria era uma criança muito difícil que, até mesmo os pais, não tinham controle sobre ela, já que cometia atitudes recrimináveis. E, através dessas travessuras, a menina Maria acabou revoltando seus brinquedos que, por meio da imaginação e da fantasia, encontraram um meio estratégico para moldar o comportamento e a educação da menina. Dessa maneira, os brinquedos passaram a colaborar como um ponto positivo que forneceu para os pais a alegria de ver a mudança no comportamento e na educação da filha.

Diante das investidas violentas das bonecas contra si, num processo educativo, Maria, personagem de Maria e seus bonecos, assim como Fernandinho, de As aventuras do avião vermelho, promete a mudança de comportamento. "-Meu Jesus! me ajude - (pensou). Eu prometo que - ai! está doendo demais! - Nunca mais faço maldade! Mais devagar, seu polichinelo! Prometo ser boazinha, prometo dar a Clarinha a metade de todos os doces que eu ganhar" (PEREIRA, 1943, p. 22).

Aqui, percebemos que a menina Maria está se arrependendo de suas atitudes, por estar passando por um castigo dos seus brinquedos. Com isso, a autora Lúcia Miguel Pereira, demonstra a liberdade de escolha da criança, refletindo sobre sua atitude, a qual contribui para que o pequeno leitor exerça a reflexão e, consequentemente, a aprendizagem, ou seja, a criança percebe que as más atitudes podem gerar consequências negativas. Também a personagem Fernandinho vê, por meio do brinquedo, a negociação travada pelo pai a fim de lhe revelar outros prazeres e, ao mesmo tempo, mudar os seus comportamentos de modo que agrade o pai.

Nessa perspectiva, as narrativas apresentadas de Lúcia Miguel Pereira e de Érico Verísssimo demonstram intensa afinidade com os contos populares e de fadas por utilizar fatos cotidianos a fim de provocar o deleite e, consequentemente, a aprendizagem. Assim, acredita-se, cada vez mais, na importância e na influência dos contos de fadas para o desenvolvimento da imaginação infantil. Por conseguinte, notamos que a comparação das obras permite sugerir que o lúdico, na educação infantil, é uma ferramenta que pode dar mais vida e prazer no processo da aprendizagem, pois oferece um desenvolvimento sadio e harmonioso, com o qual a criança é capaz de interagir, participar e expressar sua opinião no meio em que vive. Como forma de viver essas experiências imaginárias, em Maria e seus bonecos, o boneco ganha vida e sai pela janela voando, segurando a mão de menina. Neste momento, concretiza-se um dos desejos de criança, que é poder voar. "Maria sentiu um frio na barriga, mas apertou bem a mão do boneco, e foi andando com ele. Andando é modo de dizer: corriam, voavam, iam mais depressa do que avião. Passaram em cima de casas, de rios, de campos, de florestas, num instante" (PEREIRA, 1943, p. 29).

De acordo com Dirce Loremier Fernandes (2003), a função lúdica da literatura infantil decorre de 
seu caráter incentivador de jogos, com palavras ou figuras, que lembra brinquedos e divertimentos. Sendo assim, Nelly Novais Coelho corrobora com essa afirmação reforçando que a literatura infantil "funde os sonhos e a vida prática, o imaginário e o real, os ideais e sua possível/impossível realização" (COELHO, 2000, p. 27). Para a concretização desse plano imaginário no mundo real, tanto Veríssimo como Pereira partem do elemento mais comum na vida da criança que é o brinquedo.

\section{Conclusão}

Assim como Lúcia Miguel Pereira, Érico Veríssimo deixa manifesto em sua obra que a brincadeira é algo inerente à criança, pois é a forma de trabalhar, refletir e descobrir o mundo que o cerca. $\mathrm{Na}$ narração de As aventuras do avião vermelho, notamos essa interação entre realidade e fantasia promovida por meio dos brinquedos: "O urso pegou o pote de geléia e a lata de biscoitos. O boneco pegou o cacho de bananas e a mala do capitão. E entraram todos no avião... Correu pelo quarto, passou por baixo da cadeira e subiu... Passou pela janela e saiu voando em direção das estrelas" (VERÍSSIMO, 2003, p. 19).

Percebemos que a presença dos brinquedos para o menino Fernando, em As aventuras do avião vermelho, de Érico Veríssimo quanto para a menina Maria, de Maria e seus bonecos, de Lúcia Miguel Pereira serviram para estimular bons comportamentos e também desenvolver novos processos de desenvolvimento infantil. Sendo assim, tanto os bonecos quanto o avião presente nas obras proporcionaram desenvolvimento na capacidade e na habilidade de suas ações na medida em que as crianças executam e vivem suas próprias ações e experiências. Com isso, percebe-se que as crianças criam comportamentos mais elaborados que 0 habitual em suas idades, tentando assim, imitar os adultos nas atividades da vida real decorrente da própria situação imaginária.

A imaginação pode contribuir para 0 desenvolvimento da criatividade e da sensibilidade infantil, uma vez que o conto de fadas é visto como a narrativa mais adequada para o leitor mirim, pois permite a aproximação do mundo mágico com o real. Além disso, permite à criança buscar meios que estabeleçam uma relação do seu "eu" com o meio social, pois a criança acredita que, da mesma forma que as histórias solucionam os conflitos apresentados nos contos, sua participação através da leitura facilitam seu entendimento ao descobrir novas dimensões imaginárias que ela não poderia descobrir por si só, como postula Nelly Novais Coelho (1987). Sob tais pressupostos, Bárbara Vasconcelos de Carvalho corrobora com esta afirmação com as seguintes palavras:

Objetivo das estórias: socializar, recrear, formar, informar, educar a atenção, enriquecer a linguagem, estimular a imaginação e a inteligência, despertar emoções, desenvolver o sentimento de compreensão e a simpatia humana e despertar o senso estético e artístico-literário, formar o hábito da leitura, sobretudo ensinar a "ouvir". Os objetivos das estórias ou contos infantis visam a três aspectos: literário-recreativo, psicológico e educativo. $\mathrm{O}$ aspecto psicológico apresentam implicações específicas: ajuda a resolver conflitos emocionais e as diferenças individuais; determina a origem inconsciente ou desconhecida do comportamento (COELHO, 1987, p.57).

Pelo que se nota, a literatura infantil pode ser um instrumento valioso de crescimento intelectual, já que estimulam a novas criações e experiências. Crianças com pouca imaginação são pouco criativas. É preciso, pois, muita brincadeira e jogos para estimular a imaginação, pois se a literatura parte das experiências cotidianas e dos elementos do mundo infantil contribui para formação intelectual e criativa da criança, além de libertá-la de suas tensões. Em ambas as obras, notamos como as crianças são estimuladas pelos brinquedos. Tanto Lúcia Miguel Pereira quanto Érico Veríssimo retratam como os brinquedos fazem parte do universo infantil estimulando a percepção e o pensamento do pequeno leitor permitindo assim mais poder à imaginação. 


\section{Referências}

ALMEIDA, Edwirgens A. R. Lopes. O legado ficcional de Lúcia Miguel Pereira: Escritos da Tradição. Florianópolis: Ed. Mulheres, 2011. 255p.

ALMEIDA, Edwirgens Aparecida Ribeiro Lopes de. A literatura infantil de Lúcia Miguel Pereira - Uma escrita da tradição? In: OLIVA, O. P.. Contemplações de Minas Gerais na Literatura. Belo Horizonte: O Lutador, 2017, p. 33-46.

ARIÈS, Philippe. História social da criança e da família. Tradução de Dora Flaksman. 2.ed. (Reimpr.). Rio de Janeiro: LTC, 1981.

AZEVEDO, Ricardo. Literatura infantil: origens, visões da infância e traços populares. In: Presença Pedagógica. V. 5, nº 27, Jan/Fev/1999.

BUENO, Luis. Nação, Nações: os modernistas e a geração de 30. Disponível em https://www.revistas.usp.br/viaatlantica/article/view /49789/53893. Acesso em: 28 de ago.2017.

COELHO, Nelly Novaes. Literatura infantil: história, teoria, análise. 3.ed. refundida e ampliada. São Paulo: Edições Quiron Ltda, 1984.

COUTINHO, Afrânio. A literatura no Brasil. 5. ed. São Paulo. Ed. Global, 1999.

CUNHA, Antonieta. Literatura infantil: teoria e prática. SP: Ática, 1994.

PEREIRA, Lúcia Miguel. Maria e seus bonecos. Capa e ilustrações Santa Rosa. 33p.

CARVALHO, Bárbara Vasconcelos. A literatura infantil. 5. ed. São Paulo. Ed. Global, 1987.

VERÍSSIMO, Érico. As aventuras do avião vermelho. Ilustrações de Eva Furnari. São Paulo: Companhia das Letrinhas, 2003.

ZILBERMAN, Regina. LAJOLO, Marisa. Literatura infantil brasileira. História e histórias. ed: 6a․ São Paulo. ed. Ática 2007.

\section{COMO CITAR ESSE ARTIGO}

RIBEIRO LOPES DE ALMEIDA, Edwirgens Aparecida; QUEIROZ DE OLIVEIRA, Regina. O papel da imaginação como estratégia educativa em Maria e seus bonecos e As aventuras do avião vermelho. Signo, Santa Cruz do Sul, v. 43, n. 78, nov. 2018. ISSN 1982-2014. Disponível em: $<$ https://online.unisc.br/seer/index.php/signo/article/view/12031>. Acesso em: doi: https://doi.org/10.17058/signo.v43i78.12031. 